\title{
DROUGHT MITIGATION THROUGH HYDROGEL APPLICATION IN RICE (Oryza sativa L.) CULTIVATION
}

\author{
Boreddy Surya Prakash Reddy ${ }^{1, *}$, Sriram Vasudevan ${ }^{1}$, Shibu K Mani ${ }^{1}$, \\ Sirisha Uppaluri ${ }^{1}$, M Sudakar ${ }^{2}$
}

${ }^{1}$ Department of Civil Engineering, CHRIST (Deemed to be University), School of Engineering and Technology, Bengaluru 560074, India

${ }^{2}$ Department of Agronomy, Pendekanti Krishi Vigyan Kendra, Kurnool 518124, India

Received - September 13, 2021; Revision - November 23, 2021; Accepted - December 12, 2021

Available Online - December 30, 2021

DOI: http://dx.doi.org/10.18006/2021.9(6).727.733

\section{KEYWORDS \\ Drought \\ Mitigation \\ Hydrogel \\ Sustainability \\ Agriculture \\ Rice \\ Soil conditioning}

\begin{abstract}
Sustainability in irrigation is an essential step towards responsible water consumption. In recent years, many studies have sketched climate-resilient agricultural practices to fight drought and uncertain rainfall patterns. Major rain-fed crops such as paddy and wheat require aid when there are abnormal dry spells. To mitigate the loss of crops from such events, superabsorbent polymers can be used. Soils amended with hydrogel or Superabsorbent polymer (SAP) retain moisture during drought to prevent loss of water through evaporation and percolation. This allows the crop to grow with less shock from drought. This study compares rice (Oryza sativa L.) growth rate under application (treatment groups) and non-application (control groups) of hydrogel, considering their high-water requirement. NDLR07 (recently developed) and BPT5204 (local variety) rice varieties were chosen for the current study. Randomized controlled trials were performed for each variety on a control group (NC \& BC) and 3 treatment groups with $20 \%$ (NT20 \& BT20), 40\% (NT40 \& BT40), and 60\% (NT60 \& BT60) deficit water supplies respectively. N, T, C refers to seed type, treatment group, control group respectively. Intermittent drought condition was imposed for 14 days to assess the resilience of crops. The water retention capacity of the sandy loam soil was better for treatment groups by $20 \%$ than control groups even at an average temperature of $40{ }^{\circ} \mathrm{C}$. Treatment groups continued growing through the drought phase and after, while control groups showed stagnation. Among the tested treatment groups, NT20 had the highest growth among all trials. The results of the study suggested that hydrogel application can help to combat droughts and thereby contribute to sustainable agricultural production by restricting the involvement of climate changes.
\end{abstract}

* Corresponding author

E-mail: boreddyspr1@gmail.com (Boreddy Surya Prakash Reddy)

Peer review under responsibility of Journal of Experimental Biology and Agricultural Sciences.

Production and Hosting by Horizon Publisher India [HPI] (http://www.horizonpublisherindia.in/).

All rights reserved.
All the articles published by Journal of Experimental Biology and Agricultural Sciences are licensed under a Creative Commons Attribution-NonCommercial 4.0 International License Based on a work at www.jebas.org.

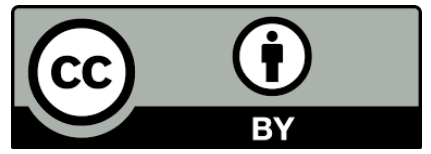




\section{Introduction}

Climate change might shift the paradigms of living conditions on earth in the next hundred years (IPCC, 2019). The frequency of droughts due to climate change is expected to increase in the coming decades, which adversely affects the growth of major food crops. In this scenario, sustainability towards food security should be ensured by checking the water consumption of high-water consuming crops concerning climate change. Rice ( $O$. sativa) is a crop that consumes a high amount of water and is a staple diet globally that demands attention (Chun et al., 2016). Various strategies such as aerobic cultivation of rice (Rehman et al., 2011), subsurface drip irrigation (Parthasarathy et al., 2018), deficit irrigation (Pirmoradian et al., 2004), water management techniques, use of tension-meter (Kalyanasundaram et al., 2021), use of drought resistance cultivar, and nutrient management have been successfully put forward to mitigate the adverse effects of droughts on agricultural productivity. The application of soil conditioners is one of the methods which enables the soil to retain moisture for extended periods (Kalhapure et al., 2016, Neethu et al., 2018).

Superabsorbent polymers (SAPs) or hydrogels can be used as soil conditioners to amend sandy soils to prevent accelerated evaporation and leaching of nutrients and water beyond the root zone of plants. Hydrogels are composed of hydrophilic homopolymer ( $N$-iso-propyl methacrylamide) or copolymer networks and can swell in water or physiological fluids. Chemical cross-links (covalent bonds) or physical junctions (e.g., secondary forces, crystallite formation, chain entanglements) provide the hydrogels' unique swelling behavior in a three-dimensional structure (Ahmed, 2015). The swelling enables hydrogel to act as a water reservoir for plants in the root zone for uptake during water stress. The agricultural application of hydrogels has been extensively studied by Guilherme et al. (2015). Further, Rehman et al., (2011), studied its application on rice and reported $18 \%$ higher growth in soil treated with hydrogel than ordinary soil conditions. In another study, Prakash et al. (2021), suggested that a up to $60 \%$ deficit water supply could give better crop growth for the initial stages under hydrogel application. Similarly, Sen et al. (2019), showed that hydrogel allowed sustained paddy crop growth under drought conditions. This paper aims to present the crop growth pattern of rice under the influence of hydrogel with a deficit supply of water and induced drought conditions to ascertain the extent of reduction of water consumption of paddy.

\section{Materials and Methods}

\subsection{Seed variety}

For this study, seeds of 2 rice varieties viz., BPT5204 and NDLR07 were selected. BPT5204 is the locally used variety, while NDLR07 was the recently developed drought-resistant rice variety (Jayalakshmi et al., 2020). NDLR07 showed a greater yield and economic benefit when compared with BPT5204. The study on seed growth, as influenced by hydrogel, would give a greater clarity towards climactic action in agricultural practices.

\subsection{Field conditions}

The present study was conducted at the experimental station of Krishi Vigyan Kendra (an integral part of the National Agricultural Research System in India), Banaganapalli, Andhra Pradesh (Figure 1). The experiments were conducted during the rabi season (FebApril 2021) under sandy loam soil (75\% sand, $12 \%$ silt, and $13 \%$
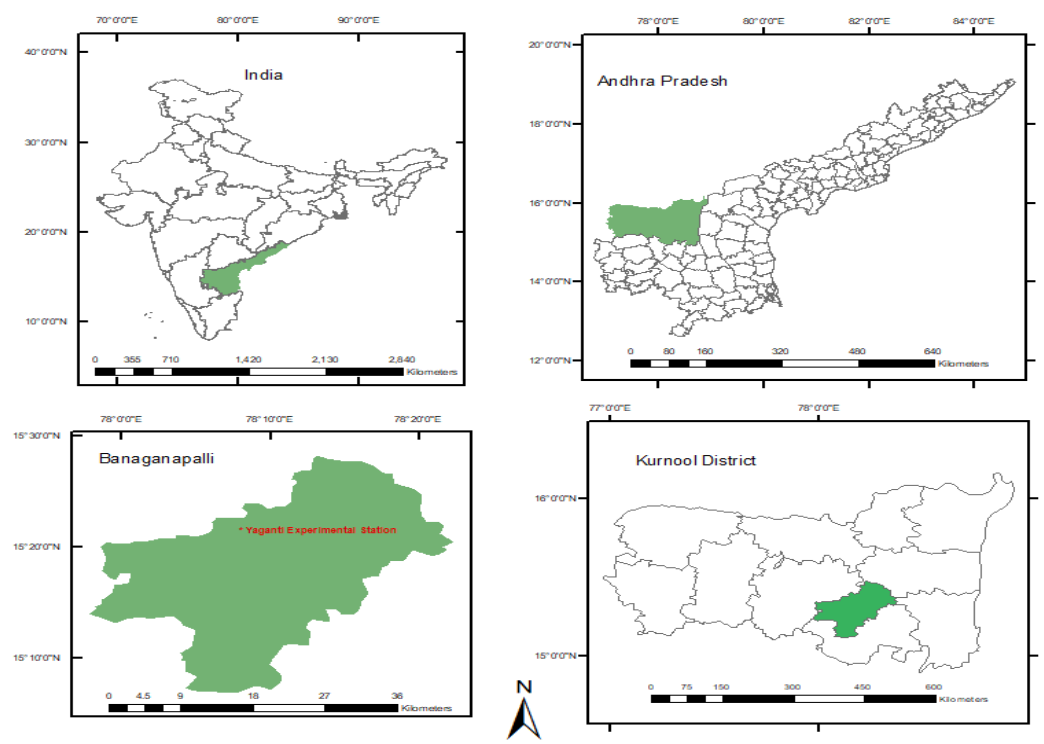

Figure 1 Location of Yaganti field experimental station of Krishi Vigyan Kendra.

Journal of Experimental Biology and Agricultural Sciences http://www.jebas.org 


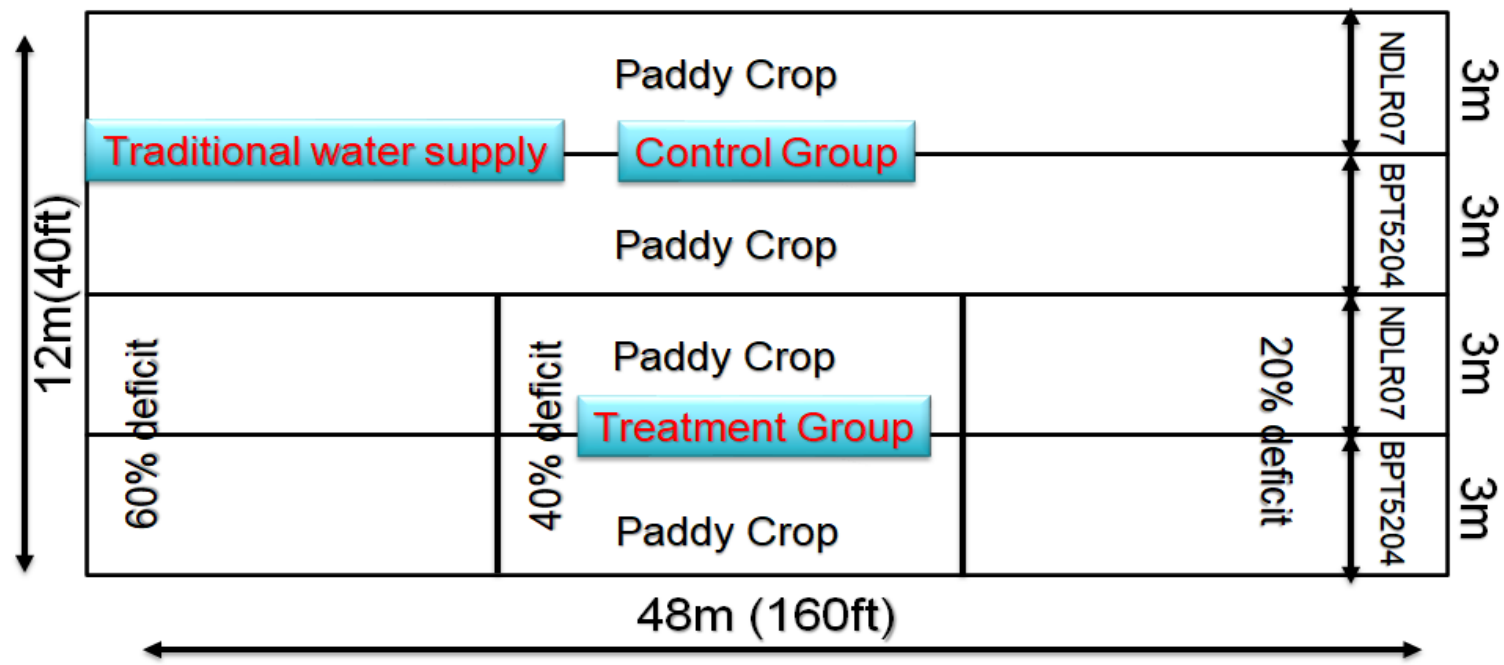

Figure 2 Layout of experimental groups for comparative study in the field for NDLR07 and BPT5204. Based on water supply, the crops were grouped as BC (BPT5204 control) and NC (NDLR07 control); while BT20, BT40, BT60 were used for BPT5204 treatment groups; and NT20, NT40, NT60 used for NDLR07 treatment groups with 20\%, 40\%, and 60\% deficit water supply respectively for each variety.

clay). Randomized controlled trials with Control and treatment groups were laid out as shown in Figure 2. The total net plot size of the experimental setup is 576 sq. m. Treatment groups were grown in soil amended with hydrogel and 3 different water supply deficits as done in a previous study (Prakash et al., 2021). The control group was supplied with $1 \mathrm{~cm}$ of water for 28 days after sowing (DAS); $2.2 \mathrm{~cm}$ of water from 28-45 DAS; and $0.5 \mathrm{~cm}$ of water till the maturation crop. The treatment groups were supplied at varying intervals to meet the deficit conditions.

Irrigation was withheld for two weeks in the absence of rain to induce a drought condition so that the tolerance of crops to water stress could be observed and compared for correlation with hydrogel application. A drought situation was created between the 100 DAS and 114 DAS (Days after sowing). Harvesting was carried out manually in the second week of June 2021, when panicles were fully ripened.

\subsection{Sowing techniques and hydrogel application}

The method of direct sowing (Sudharani et al., 2019) was adopted in the study and a drum seeder was used for seeding. These drum seeders (Figure 3) consisted of four plastic seed drums mounted on a shaft, ground wheels, floats, and a handle. The seed drum was cylindrical and had a diameter of $200 \mathrm{~mm}$. There were nine seed metering holes (funnel-shaped) of $8 \mathrm{~mm}$ diameter along the circumference of the drum at both ends, with a row to row spacing of $200 \mathrm{~mm}$. The direct seeding technique was adopted to reduce transplantation costs and eliminate the high initial water demand for transplanted rice.

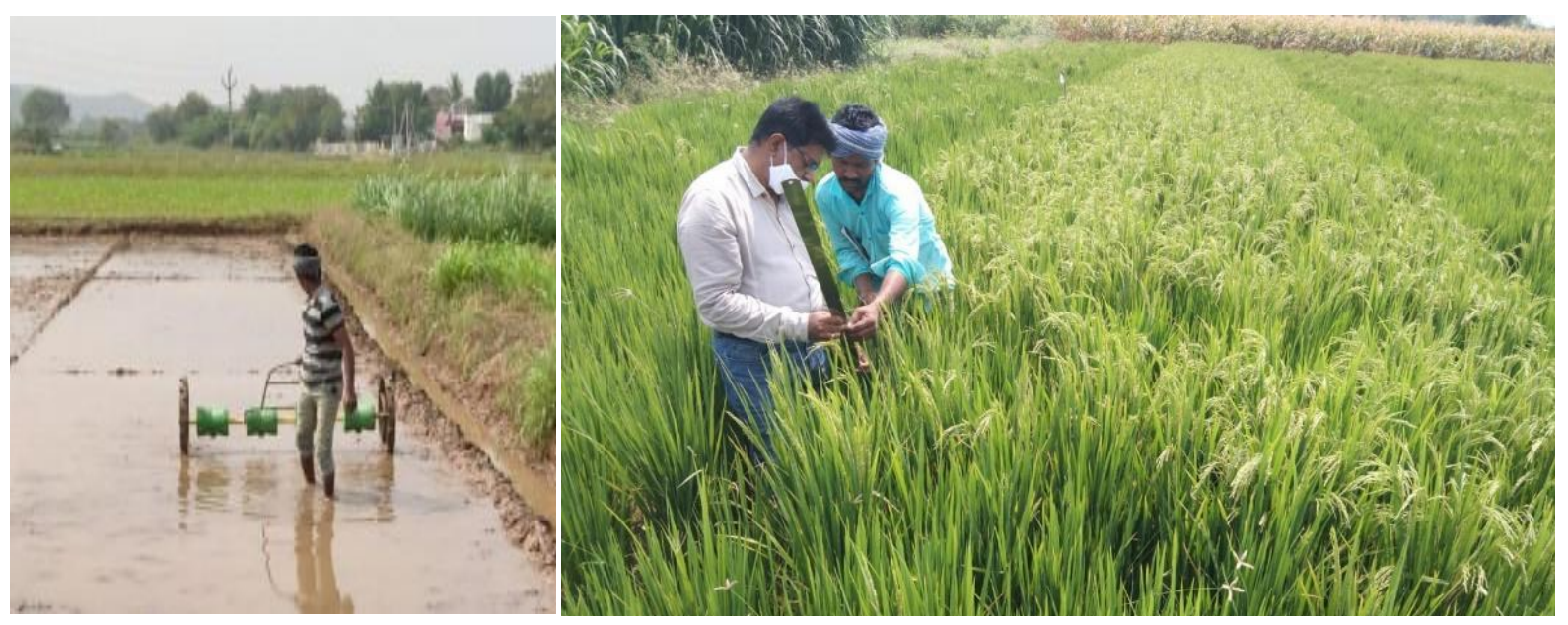

Figure 3 (Left) Drum seeder used in the experiment. (Right) Crop height measurement and examination

Journal of Experimental Biology and Agricultural Sciences http://www.jebas.org 
The hydrogel was applied manually at the time of soil preparation at $2.5 \mathrm{~kg} / \mathrm{ha}$ as per ICAR recommendations (Lather et al., 2015; Kalhapure et al., 2016). Sprouted paddy seeds were sown using the drum seeder. A fertilizer dose of 133-85-62 kg NPK/ha was applied. Weed Management was done through a cono-weeder (Sudharani et al., 2019), and it was run in the direction in which the drum-seeder was pulled. All other agronomic practices were kept normal and uniform for all the treatments. The treatment group received a $40 \%$ deficit supply of all the supplies to the crop compared to the control group.

\subsection{Statistical Analysis}

Collected data were statistically analyzed using one-way analysis of variance (ANOVA) in SAS software.

\section{Results}

The plant growth trend in terms of height is presented in Figure 4 (A and B). In both varieties of rice (BPT5204 and NDLR07), a clear difference in plant height is seen between the experimental groups. The differences in the growth rate of each treatment group in the growth period are represented in fig. 4A and 4B.

The best-fit curves of the $3^{\text {rd }}$ degree showed the highest correlation. The equations of plant height for BPT5204 as a function of the number of days are as follows:

PB20 $=-7.728 \times 10^{-5}\left(X^{3}\right)+0.01306\left(X^{2}\right)+0.4031(X)-$ 1.185 ,

PB40 $=-7.375 \times 10^{-5}\left(X^{3}\right)+0.01325\left(X^{2}\right)+0.2294(X)+$ 0.8474 ,

PB60 $=-4.996 \times 10^{-5}\left(X^{3}\right)+0.00925\left(X^{2}\right)+0.3566(X)-$ 0.6088 ,

$\mathrm{PBC}=-8.312 \times 10^{-5}\left(\mathrm{X}^{3}\right)+0.0144\left(\mathrm{X}^{2}\right)+0.2595(\mathrm{X})+$ 0.2856 ,

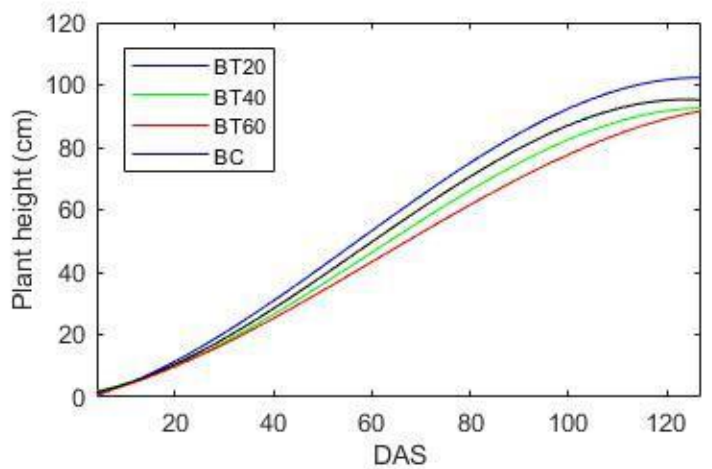

(A)
Where PB20, PB40, PB60, and PBC are the plant heights of BT20, BT40, BT60, and BC groups respectively; $\mathrm{X}$ is DAS. The $\mathrm{R}^{2}$ values were 0.9971, 0.9971, 0.9939, and 0.9979; the RMSE values were $2.0015,2.6064,2.4618$, and 1.6032 , respectively for eq.1, 2, 3 , and 4

In BPT5204 (Figure 4A), at the end of the harvest period, the treatment group with a $20 \%$ deficit supply of water had the highest growth. Compared to the control group, the growth of BT20 was higher by $9 \%$, BT40 lesser by $1 \%$, and BT60 lesser by $3 \%$ at the end of the harvest period. From Figure 4 (A), BT40 and $\mathrm{BC}$ show a similar growth trend with comparable plant height values. Throughout the cultivation period, the growth percentage gradually reduced for all experimental groups. Figure 5(A) shows that BT60 exhibited the lowest and highest growth rates among all groups. The growth rate varies in a wavy pattern, with peaks and troughs. BT20 exhibited 4 peak rates at an interval of 24-32 days with the highest peak at 48 DAS. BT40 showed 5 peaks at intervals of 16-32 days with the highest at 48 DAS. BT60 showed 4 peaks at intervals of 16-24 days with the highest at 72 DAS. BC showed 3 peaks at intervals of 16-24 days and a gradual decrease in growth rate after the 3rd peak. During the induced drought period from 100 DAS to 113 DAS, the treatment groups showed no significant decrease in growth rates as seen in the control group.

In NDLR07, NT20 showed the highest plant height at the end of the harvest period $(105.2 \mathrm{~cm})$. The best fit $3^{\text {rd }}$ degree equations for the plant height of NDLR07 variety are given below:

PN20 $=-9.198 \times 10^{-5}\left(X^{3}\right)+0.01378\left(X^{2}\right)+0.5554(X)-$

(2) 1.185 ,

PN40 $=-1.237 \times 10^{-4}\left(X^{3}\right)+0.02456\left(X^{2}\right)+0.3361(X)-$

(3) 5.359 ,

PN60 $\left.=-5.77 \times 10^{-5}\left(X^{3}\right)+0.01044 X^{2}\right)+0.3002(X)-4516$,

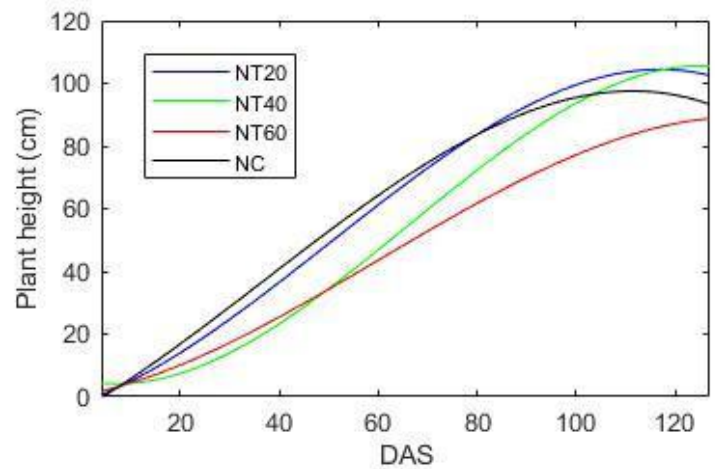

(B)

Figure 4 Average plant height recorded at regular time intervals throughout the growth period for the variety BPT5204 (A) and NDLR07 (B)

Journal of Experimental Biology and Agricultural Sciences

http://www.jebas.org 
$\mathrm{PNC}=-7.317 \times 10^{-5}\left(\mathrm{X}^{3}\right)+0.008127\left(\mathrm{X}^{2}\right)+0.9145(\mathrm{X})-$ 4.048 ,

Where PN20, PN40, PN60, and PNC are the plant heights of NT20, NT40, NT60, and NC; $X$ is DAS. The $R^{2}$ values were 0.9964, 0.9838, 0.9972, and 0.9945; while RMSE values were $2.3143,4.9411,1.6337$, and 2.6947 , respectively for eq. $5,6,7$, and 8 . The order of plant height at the end of the harvest period was NT20 $>$ NT40 $>$ NC $>$ NT60 (Figure 4B). Compared to the control group, the growth rate of NT20 was $8.1 \%$ higher than that of NT40 1.1\% (lower) and that of NT60 3.5\% (lower). The highest peak growth rate was seen for NT20 at 72 DAS (Figure 5B). The growth rate trends of NT20 and NT40 were similar, while those of NT60 and NC were also found similar. After the induced drought period, the treatment groups continued to show an increasing growth rate, while the decreasing trend of $\mathrm{NC}$ growth rate continued even with adequate water supply. NT20 showed 5 peaks at 16-24 days interval; NT40 showed 6 peaks with a wide gap of 24 days between the first 2 peaks, and then reaching peaks at 16 days interval for the rest; NT60 showed 6 peaks too with similar intervals as NT40; NC showed 3 peaks at 16 to 24 days interval and gradually declined after the 3rd peak.

In both seed types (BPT5204 and NDLR07), the least growth was seen in groups with a $60 \%$ deficit supply of water, while the highest growth was seen in the groups with a $20 \%$ deficit supply of water. The control group had only 3 peaks as opposed to 4 to 6 peaks in the treatment groups, after which the control group only showed a decline in growth rate as opposed to the treatment groups which continued to show peaks and increased growth rate. During the induced drought period, in both varieties of rice, the growth rate was not significantly affected. There was even an increase in the growth rate for some cases (BT40 and NT20).
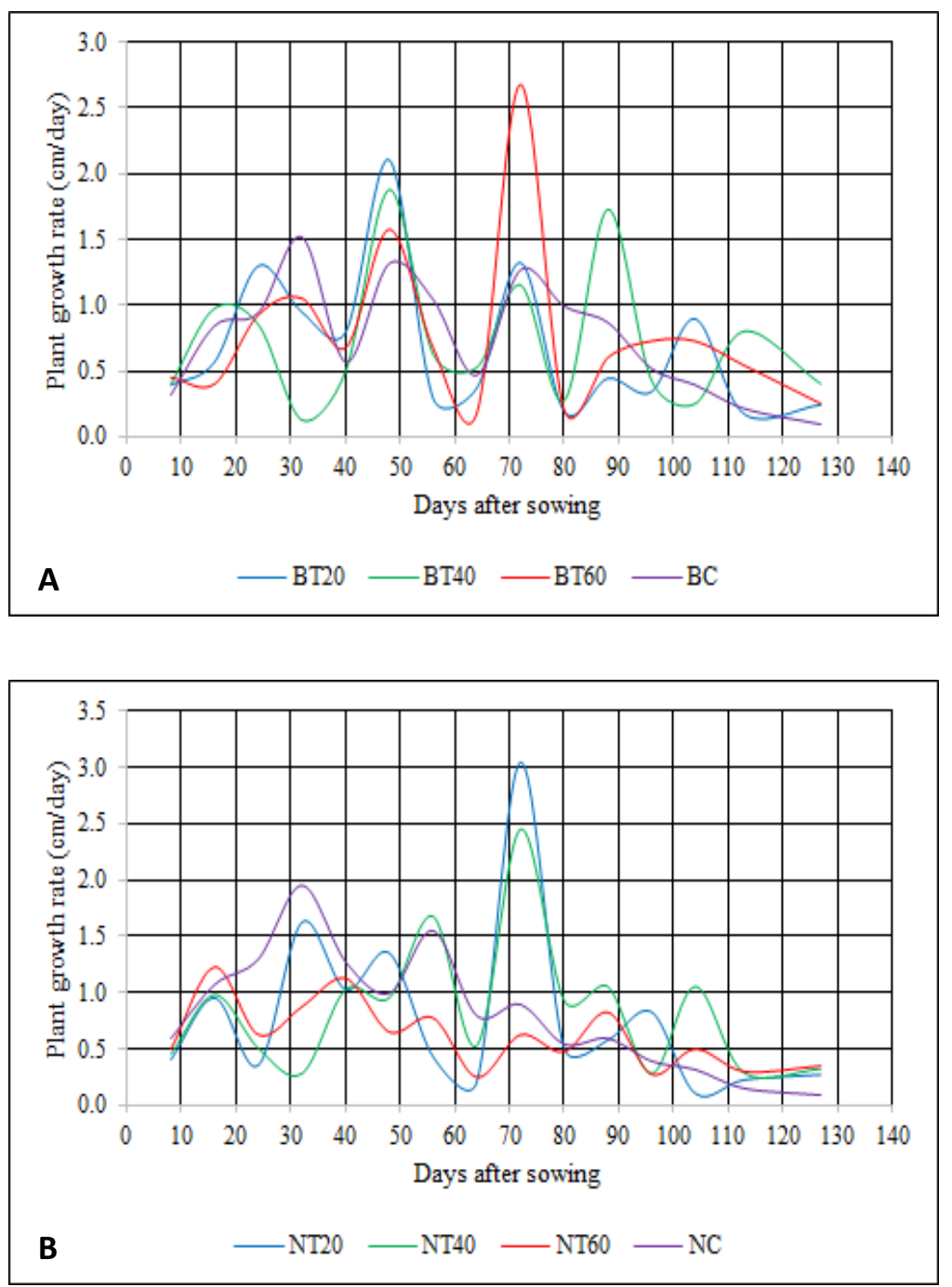

Figure 5 Plant growth rate expressed in $\mathrm{cm} / \mathrm{day}$, for the duration of induced drought in BPT5204 (A) and NDLR07 (B) for treatment groups.

Journal of Experimental Biology and Agricultural Sciences http://www.jebas.org 


\section{Discussion}

NDLR07 (NT20) performed the best among all experimental groups, with a growth of up to $105.2 \mathrm{~cm}$ at 127 DAS. The high growth could be because of NDLR07's adaptability to drought (Jayalakshmi et al., 2020). It is also evident that drought conditions had some effect on the growth rate in the groups treated with hydrogel. Even under a $60 \%$ deficit of water supply, with an induced drought period of 14 days, the survival of paddy crops was not affected. The crop growth rate towards the end of the reproductive stage directly impacts the yield as it involves the growth of spikelets (Takai et al., 2006). Considering the same stage in the treatment groups and relating crop growth rate to the plant height growth rate, the rate of growth continues to increase instead of a decrease in control groups. This suggests that treatment with hydrogel could increase yield, compensating for damage (if any) from a lack of water. Sen et al. (2019), showed that hydrogel application helped rice crops survive drought for longer durations. This was attributed to better root growth conditions due to hydrogel application. The formation of a rootsoil-water matrix at the root zone, during induced drought, suggested that the roots are better preserved with a continued supply of water (Agaba et al., 2011). A similar study by Kurrey et al. (2018) reported concurrent results when the root system is under shock from drought, stomatal cells close, leading to a decreased growth rate (Kim et al., 2020). The presence of hydrogel prevents this as the roots are protected from moisture stress. Under normal conditions, the yield of crops treated with hydrogel increases significantly (Roy et al., 2019). In a climate change scenario where rice production is affected adversely, hydrogel application along with other mitigation methods could contribute to a sustainable support system to combat drought events (Soundharajan \& Sudheer, 2009; Uga et al., 2013; Li et al., 2015).

\section{Conclusion}

Insights were derived in the present study on the potential positive effects of Hydrogel application as a drought mitigation method. The hydrogel can amend the root-soil-water relationship in crop systems to enhance crop growth. The use of NDLR07 as a droughtresistant crop amended with hydrogel would prevent damage and loss from drought conditions. BPT5204 variety has also shown resistance to drought conditions when amended with hydrogel. The increase in productivity would help ensure sustainability, thereby allowing the farmers to fetch benefits. In the present study, the productivity of crops based on plant height has been established with mathematical relations. Though the third-degree polynomial matches with a high correlation, subsequent research should be done using parameters such as biomass, water schedules, temperature, and humidity to deepen the understanding of hydrogel influences on crop growth.

\section{Acknowledgements}

We are grateful to CHRIST (Deemed to be University) for supporting the study. The support given by Krishi Vigyan Kendra through providing facilities for field experimental setup is greatly acknowledged.

\section{Conflict of Interest}

The authors state that they have no conflict of interest.

\section{References}

Agaba H, Orikiriza LJ, Obua J, Kabasa JD, Worbes M, Hüttermann A (2011) Hydrogel amendment to sandy soil reduces irrigation frequency and improves the biomass of Agrostis stolonifera. Agricultural Sciences 2(04): 544.

Ahmed EM (2015) Hydrogel: Preparation, characterization, and applications: A review. Journal of Advanced Research 6(2):105121.

Chun JA, Li S, Wang Q, Lee WS, et al. (2016) Assessing rice productivity and adaptation strategies for Southeast Asia under climate change through multi-scale crop modeling. Agricultural Systems 143:14-21.

Guilherme MR, Aouada FA, Fajardo AR, Martins AF, et al. (2015) Superabsorbent hydrogels based on polysaccharides for application in agriculture as soil conditioner and nutrient carrier: A review. European Polymer Journal 72: 365-385.

IPCC special report (2019) Climate Change and Land: an IPCC special report on climate change, desertification, land degradation, sustainable land management, food security, and greenhouse gas fluxes in terrestrial ecosystems. Retrieve from https://reliefweb.int/sites/reliefweb.int/files/resources/4.-

SPM_Approved_Microsite_FINAL.pdf.

Jayalakshmi M, Babu GP, Chaithanya BH (2020) On Farm Testing of Rice Variety NDLR-7 as an Alternative to Traditionally Grown BPT-5204 in Kurnool District of Andhra Pradesh. Agricultural Science Digest (40):392-395.

Kalhapure A, Kumar R, Singh VP, Pandey DS (2016) Hydrogels: a boon for increasing agricultural productivity in water-stressed environment. Current Science 111 (11): 1773-1779.

Kalyanasundaram D, Arthi E, Kumar KS, Sri SH (2021) Yield maximization of direct sown rice (Oryza sativa 1.) under water constraint situation. Journal of Applied and Natural Science 13(1): 373-376. 
Kim Y, Chung YS, Lee E, Tripathi P, Heo S, Kim KH (2020) Root response to drought stress in rice (Oryza sativa L.). International Journal of Molecular Sciences 21(4):1513.

Kurrey D, Singh RK, Rajput RS (2018) Effect of Hydrogel and Trichoderma on root growth and water productivity in rice varieties under Rainfed Conditions. Research Journal of Agricultural Sciences 9: 210-212.

Lather VS, Ashwani K, Chopra NK, Choudhary D, Yadav RN, Seth R (2015) Novel herbal hydrogel Tragacanth-Katira gel and farmer's friendly seed priming-hydrogel coating technology for water saving, making agriculture sustainable and resilient to climatic variability. International Journal of Tropical Agriculture 33(2): 1167-1171.

Li T, Angeles O, Radanielson A, Marcaida M, Manalo E (2015) Drought stress impacts of climate change on rainfed rice in South Asia. Climatic Change 133(4): 709-720.

Neethu TM, Dubey PK, Kaswala AR (2018) Prospects and applications of hydrogel technology in agriculture. International Journal of Current Microbiology and Applied Sciences 7(5): 3155 3162 .

Parthasarathi T, Vanitha K, Mohandass S, Vered E (2018) Evaluation of drip irrigation system for water productivity and yield of rice. Agronomy Journal 110(6): 2378-2389.

Pirmoradian N, Sepaskhah A, Maftoun M (2004) Deficit irrigation and nitrogen effects on nitrogen-use efficiency and grain protein of rice. Agronomie 24(3):143-153.

Prakash S, Vasudevan S, Banerjee A, Joe AC, Reddy GKNG, Mani SK (2021) Sustainable water consumption of rice (Oryza sativa L.) as influenced by superabsorbent polymer in water stressed conditions. International Journal of Modern Agriculture 10(1): 857-866.

Rehman A, Ahmad R, Safdar M (2011) Effect of hydrogel on the performance of aerobic rice sown under different techniques. Plant, Soil and Environment 57(7): 321-325.

Roy T, Kumar S, Chand L, Kadam DM, et al. (2019) Impact of Pusa hydrogel application on yield and productivity of rainfed wheat in North West Himalayan region. Current Science 116(7): 1246-1251.

Sen A, Singh RK, Yadaw D, Kumari P, et al. (2019) Effect of Trichoderma and hydrogel on growth, yield and yield attributes of direct seeded rice (Oryza sativa) under rainfed condition. Indian Journal of Agricultural Sciences 89(2): 333-8.

Soundharajan B, Sudheer KP (2009) Deficit irrigation management for rice using crop growth simulation model in an optimization framework. Paddy and Water Environment 7(2):135-149.

Sudharani JS, Aruna K, Ramakrishna Babu A (2019) Drum Seeder a Promising Low-Cost Technology in Rice Production System for Small and Marginal Farmers of Mahabubnagar District, India. International Journal of Current Microbiology and Applied Sciences 8(2):784-788.

Takai T, Matsuura S, Nishio T, Ohsumi A, Shiraiwa T, Horie T (2006) Rice yield potential is closely related to crop growth rate during late reproductive period. Field Crops Research 96(2-3): 328-335.

Uga Y, Sugimoto K, Ogawa S, Rane J, et al. (2013) Control of root system architecture by DEEPER ROOTING 1 increases rice yield under drought conditions. Nature Genetics 45(9):1097-1102. 